\title{
HIV/aids no Brasil: feminização da epidemia em análise
}

Luciana Narciso da Silva Campany ${ }^{1}$, Daniela Murta Amaral ${ }^{2}$, Roberta Nascimento de Oliveira Lemos dos Santos ${ }^{1}$

1. Fundação Oswaldo Cruz, Rio de Janeiro/RJ, Brasil. 2. Universidade Estácio de Sá, Rio de Janeiro/RJ, Brasil.

\section{Resumo}

Este trabalho analisa a feminização da epidemia de HIV/aids no Brasil e a importância de considerar esse processo no planejamento de ações em saúde pública. A pesquisa foi desenvolvida por meio de revisão de literatura e estudo de dados oficiais do Ministério da Saúde. Os resultados mostram que ações eficazes no combate à infecção por HIV/aids entre as mulheres devem contemplar diferenças de gênero e condições socioculturais de cada região. $O$ artigo ainda propõe que é imprescindível um processo amplo de educação em saúde, que abranja simultaneamente homens e mulheres e tenha foco no empoderamento e no cuidado de si e do outro.

Palavras-chave: HIV. Síndrome de imunodeficiência adquirida. Feminização. Prevenção de doenças. Promoção da saúde. Planejamento em saúde. Empoderamento para a saúde.

\section{Resumen}

\section{VIH/sida en Brasil: la feminización de la epidemia en análisis}

Este artículo analiza el proceso de feminización de la epidemia de HIV/sida en Brasil y su importancia en las acciones de planificación en la salud pública. La investigación parte de una revisión de la literatura y de datos oficiales del Ministerio de Salud de Brasil. Las acciones efectivas para combatir la infección por $\mathrm{VIH} /$ sida entre las mujeres deben abordar las diferencias de género y las condiciones socioculturales en cada región. Es esencial un amplio proceso de educación sanitaria, que abarque a las poblaciones masculinas y femeninas, centrándose en el empoderamiento, el autocuidado y el cuidado de los demás dentro de las relaciones establecidas.

Palabras clave: VIH. Síndrome de inmunodeficiencia adquirida. Feminización. Prevención de enfermedades. Promoción de la salud. Planificación en salud. Empoderamiento para la salud.

\begin{abstract}
HIV/aids in Brazil: the feminization of the epidemic under analysis

This article analyzes the feminization of the HIV/aids epidemic in Brazil and the importance of considering this process when planning public health actions. This study is a literature review and also includes the analysis of official data from the Ministry of Health. The results show that effective actions to combat HIV/aids infection among women must take gender differences and the sociocultural conditions of each region into consideration. The need for a broad health education process for both men and women focusing on empowerment, self-care and caring for others can also be highlighted.
\end{abstract}

Keywords: HIV. Acquired immunodeficiency syndrome. Feminization. Disease prevention. Health promotion. Health planning. Empowerment for health. 
No início dos anos 1980, um elevado número de pacientes do sexo masculino, moradores de San Francisco e Nova York, nos Estados Unidos da América (EUA), apresentaram quadro clínico semeIhante, caracterizado pelo aparecimento de sarcoma de Kaposi, pneumonia por Pneumocystis carinii e comprometimento do sistema imunológico. Tratava-se de uma nova doença, que parecia ser infecciosa e transmissível. Casos similares ocorreram também no Haiti e na África Central, em um grupo aparentemente restrito de pessoas, composto por hemofílicos, homossexuais, usuários de drogas injetáveis e profissionais do sexo ${ }^{1,2}$.

Em 1983, os pesquisadores Luc Montagnier e Robert Gallo conseguiram isolar o vírus HIV-1 em amostras sanguíneas de pacientes doentes, e um comitê internacional recomendou o uso do termo "human immunodeficiency virus", ou "vírus da imunodeficiência humana", para denominar o causador da nova patologia, a síndrome da imunodeficiência adquirida ("sida", na sigla em português, ou "aids", em inglês) ${ }^{1}$. Em 1986, identificou-se um segundo agente etiológico, com características semelhantes ao HIV-1, que foi chamado de HIV-2 ${ }^{1,2}$.

A aids é o agravamento da infecção pelo HIV, marcado por grande comprometimento do sistema imunológico do paciente, propiciando o surgimento de doenças oportunistas causadas por vírus, bactérias, protozoários, fungos e neoplasias. Devido aos avanços nas terapias antirretrovirais, pacientes que vivem com o HIV podem se manter saudáveis por muitos anos. Porém estudos recentes têm mostrado que a infecção pelo vírus HIV inicia um processo de envelhecimento mais acelerado em comparação com pessoas saudáveis, de modo que hoje já se discute o caráter degenerativo da doença ${ }^{3}$. Um fator que possivelmente contribui para esse processo é a resposta celular somada à idade do indivíduo - que ocorre prematuramente, em resposta ao estresse - e suas relações com comorbidades e terapias antirretrovirais ${ }^{3}$.

Ao longo das décadas, o Brasil avançou na avaliação e monitoramento da doença, chegando à notificação compulsória da infecção por HIV no Sistema de Vigilância em Saúde, a partir de 2014. Hoje, a aids e a infecção pelo HIV constam na Lista Nacional de Notificação Compulsória de doenças. No entanto, apesar de todos esses esforços, boletins epidemiológicos do Ministério da Saúde (MS) ${ }^{4,5}$ revelam subnotificação de casos no Sistema de Informação de Agravos de Notificação (Sinan) e apontam falhas no registro das informações, como a inexistência de campos que permitam identificar a orientação sexual dos indivíduos e o foco exclusivo nas parcerias sexuais, nas práticas e relações afetivo-sexuais e na classificação das pessoas como cisgênero ou transgênero (pessoas cisgênero e transgênero são distinguidas a partir da concordância, no caso cis, ou discordância, no caso trans, entre a identidade de gênero autodeclarada e o sexo anatômico designado no nascimento ${ }^{6}$ ).

Essas deficiências na notificação, que inviabilizam a produção de dados importantes para compreender as vulnerabilidades à infecção pelo HIV, podem comprometer a continuidade do sistema de fornecimento de medicações e, consequentemente, a definição de estratégias mais consistentes para enfrentar a epidemia ${ }^{4}$. Dados epidemiológicos do MS mostram que foram notificados, de 2007 até junho de 2020, 342.459 casos de infecção pelo HIV no Brasil, sendo $152.029(44,4 \%)$ na região Sudeste, 8.385 (20\%) na região Sul, 5.106 (19\%) na região Nordeste, 30.943 (9\%) na região Norte, e 25.966 (7,6\%) na região Centro-Oeste. Quanto à aids, de 1980 a junho de 2020, foram identificados 1.011.617 casos, com maior concentração nas regiões Sudeste $(51 \%)$ e Sul $(19,9 \%)$, seguidas pelas regiões Nordeste (16,2\%), Norte $(6,7 \%)$ e CentroOeste (6,2\%). Observou-se diminuição do registro de casos de aids no Sinan; dos 37.308 casos de aids detectados em $2019,48,5 \%$ eram oriundos do Sinan, 8,2\% do Sistema de Informações sobre Mortalidade (SIM) e 43,3\% do Sistema de Informação de Exames Laboratoriais (Siscel) ${ }^{4}$.

Ainda que se observe um declínio no número de casos de aids no país nos últimos anos, o Ministério da Saúde ressalta que uma parcela dessa diminuição pode se dever a problemas de transferência de informações entre bases de dados de municípios, estados e Federação (esferas de gestão do Sistema Único de Saúde). Atualmente, a redução dos números também pode decorrer de uma lentidão no lançamento de dados nas bases do Sinan, em virtude da mobilização dos profissionais e serviços pela pandemia de covid-194.

No Brasil, a epidemia de HIV e de aids é composta de várias subepidemias relacionadas a diferentes realidades, decorrentes de perfis econômicos, grau de escolaridade da população e 
capacidade de investimentos na saúde. Ao longo do tempo, a infecção viral seguiu tendências diversas, como interiorização, feminização, pauperização e, nos últimos anos, juvenização e nova ascensão na população masculina, perceptíveis no aumento dos índices de infecção entre homens gays e bissexuais mais jovens ${ }^{4-8}$.

Atualmente, o Sistema Único de Saúde (SUS) disponibiliza recursos no combate à infecção pelo HIV por meio da Profilaxia Pré-Exposição (PrEP) e da Profilaxia Pós-Exposição (PEP). A primeira é indicada para pessoas mais vulneráveis ao contato com o vírus, integrantes das chamadas "populações-chave": gays, homens que fazem sexo com homens, população trans, trabalhadores(as) do sexo, pessoas que fazem sexo desprotegido com parceiros(as) que vivem com o HIV e pacientes que apresentam episódios frequentes de infecções sexualmente transmissíveis ou fazem uso repetido da PEP. Essa segunda forma de profilaxia é voltada a pessoas que, em decorrência de violência sexual, relação sexual desprotegida ou acidente ocupacional, apresentam risco de contato com o vírus. No entanto, a despeito de sua importância para compreender o perfil do indivíduo, os usos prévios dessas estratégias não são registrados no sistema de notificação ${ }^{9,10}$.

Embora o campo do feminino inclua mulheres diversas (cis, trans heterossexuais, lésbicas e bissexuais), a feminização do HIV/aids tem sido tradicionalmente tratada como questão exclusiva de mulheres cisgênero e heterossexuais. Mulheres trans - por muito tempo equivocadamente incorporadas ao segmento de homens que fazem sexo com homens ou homens gays - sempre foram reconhecidas como uma população vulnerável. Já mulheres lésbicas costumam ser compreendidas como um grupo excluído do risco de adquirir esta infecção. No entanto, mulheres cis heterossexuais (e bissexuais, quando mantêm relações afetivo-sexuais heteronormativas) só se tornaram objeto de preocupação no enfretamento da epidemia de HIV e aids após o aumento dos índices de infecção deste segmento. Esse fato revelou o alto risco de exposição a um agravo tradicionalmente associado à "promiscuidade" e a práticas homoafetivas.

Apesar de não se aprofundar na discussão sobre a diversidade de gênero e feminilidade, o presente artigo reflete sobre o processo de feminização da epidemia de HIV/aids para buscar formas de superar os diferentes contextos de vulnerabilidade desse grupo. Inferimos que a naturalização da concepção machista de que mulheres cisgênero e heterossexuais são monogâmicas e mantêm relações estáveis acabou por invisibilizar fragilidades, incluindo essas mulheres num falso território de proteção. Assim, em resumo, este artigo tem como objetivo analisar o processo de feminização da epidemia no Brasil e discutir ações de promoção e planejamento em saúde direcionadas a esse segmento.

\section{Método}

O método escolhido foi o da revisão bibliográfica narrativa, que levanta a produção científica disponível e constrói conceitos que associam conhecimentos diversos de forma harmoniosa, tornando mais explicito o tema da pesquisa. Para tanto, utilizou-se uma estratégia de busca adaptável às características do site do MS e das bases de dados pesquisadas (Literatura Latino-Americana e do Caribe em Ciências da Saúde e Scientific Electronic Library Online). As palavras-chave pesquisadas todas registradas nos Descritores de Ciência da Saúde - foram combinadas com os operadores booleanos or e and: "HIV", "aids", "feminização", "prevenção", "vigilância em saúde" e "promoção da saúde". A busca bibliográfica, realizada em fevereiro de 2021, sem filtros de limitação, retornou 100 documentos. Foram excluídos 38 documentos duplicados, e procedeu-se à leitura exploratória dos 62 documentos restantes. Por fim, restaram 30 documentos que atendiam ao objetivo do artigo. Esses textos são analisados e discutidos a seguir.

\section{A mulher na sociedade brasileira}

Desigualdades de gênero, que colocam a mulher numa situação cultural de inferioridade em relação ao homem, fazem parte da formação histórica do Brasil ${ }^{10,11}$. Analisando o papel da mulher brasileira no início do século XX, BiasoliAlves ${ }^{11}$ aponta que a submissão ao homem (pais, irmãos e maridos) era vista como desejável. No entanto, à medida que a mulher foi se escolarizando e se inserindo no mundo do trabalho, valores tradicionais que caracterizavam a "boa moça" - obediência, delicadeza no trato, habilidades manuais e pureza - começaram a ser negados. Tais valores, porém, não deixaram de existir, mas passaram a se manifestar de outras formas. 
A desigualdade de gênero torna a mulher vulnerável ao poder do homem em diversas situações: violência doméstica e sexual, violação de direitos humanos e desigualdades socioeconômicas, entre outras ${ }^{12-14}$. Essas relações assimétricas promovem uma dupla moral sexual: espera-se que as mulheres sejam recatadas e fiéis aos seus parceiros, enquanto o homem é visto como um predador sexual, mesmo quando inserido em uma relação afetiva estável ${ }^{13,15}$.

Esse padrão de comportamento, ao se constituir como norma, torna-se uma forma de opressão. Persiste em nossa sociedade a naturalização do comportamento feminino monogâmico e vinculado ao afeto, apesar de todo o avanço representado pela pílula anticoncepcional, na segunda metade do século XX, e outros métodos contraceptivos que deram à mulher maior liberdade nas vivências sexuais e busca pelo prazer, dissociando o ato sexual da reprodução.

\section{Relação HIV/aids e mulheres no Brasil}

De 2007 até junho de 2020, o Brasil contabilizou 104.824 casos de infecção pelo HIV em mulheres, o que corresponde a $30,6 \%$ dos casos registrados no período, com uma razão de 2,6 em 2019 (26 homens para cada 10 mulheres). Dentre essas mulheres, $86,6 \%$ foram infectadas em relações heterossexuais. De 1980 até junho de 2020, foram registrados 346.791 casos de aids em mulheres (34,3\% do total), com $87,8 \%$ de infecções via relações heterossexuais. A razão entre os sexos sofreu alteração ao longo dos anos, tendo sido de 15 homens para 10 mulheres entre 2002 e 2009, com aumento gradativo posterior, que se mantém desde 2017 em 23 homens para 10 mulheres $^{4}$.

O estigma de que a epidemia atingiria apenas um "grupo de risco" (homens gays, travestis e mulheres transexuais) deixou as mulheres cisgênero heterossexuais em situação de vulnerabilidade. De maneira geral, acreditava-se que apenas as profissionais do sexo - ou seja, as que tinham sabidamente múltiplos parceiros - estariam expostas à infecção. Mas o que se viu foi a feminização da epidemia dentro de um contexto de relações heterossexuais estáveis.

A naturalização do desejo sexual masculino como contínuo e inesgotável, símbolo de virilidade, faz que homens se coloquem em risco e estendam essa situação a suas parceiras fixas. Nesse contexto, toda oportunidade de relação sexual, ainda que extraconjugal, deve ser aproveitada, mesmo que no momento não haja disponibilidade de preservativos para a prática de sexo seguro ${ }^{15}$.

Para o modelo hegemônico da vivência masculina, o uso de preservativo só se justifica com a função de contracepção, ou quando a parceira é uma "mulher fácil", isto é, oferece algum tipo de risco à saúde. É comum que homens usem o método de barreira apenas no início das relações, passando à prática do sexo desprotegido quando julgam que a parceira não os trai (ainda que eles mesmos mantenham relações extraconjugais) ${ }^{15-17}$.

Por outro lado, na visão feminina, o amor tende a ser visto como sinônimo de abnegação de si mesma, e a confiança no parceiro prejudica a percepção de riscos de infecção por HIV e outras doenças sexualmente transmissíveis ${ }^{18}$. Esse excesso de confiança no outro, assim como o medo de ser mal interpretada e isso causar o fim da relação, vulnerabiliza ainda mais a mulher, dificultando a negociação com o parceiro para que o preservativo passe a ser usado nas relações sexuais ${ }^{12,17-21}$.

Carvalho e Piccinini ${ }^{22}$ afirmam que o maior índice de infecção pelo HIV se verifica entre as mulheres que se apegaram à falsa crença de que as casadas não contraem o vírus, apenas as "promíscuas". Essas mulheres se submetem aos seus maridos, delegando ao homem o papel de proteção e cuidado. Como são fiéis em suas relações, acreditam que seus cônjuges também o são, e nesse contexto não há espaço para negociar o uso de preservati$\operatorname{vos}^{23}$. Dessa maneira, o sexo seguro só é exigido em períodos de curta duração, no início da relação ou quando há desconfiança de uma traição ${ }^{16,18}$.

Entre as mulheres mais jovens a realidade não é diferente. Em pesquisa com adolescentes com idade entre 12 e 21 anos, Sampaio e colaboradores ${ }^{24}$ também encontraram relatos sobre a dificuldade de negociar o uso de preservativo com os parceiros. Nogueira, Saavedra e Costa ${ }^{25}$ chamam atenção para o fato de que entre os jovens, principalmente do sexo feminino, há perigosa tendência de acreditar que o risco de infecção por HIV é pequeno. Entre os que estão em relações estáveis, a parceria fixa e a "confiança no companheiro" são justificativas para dispensar o uso do preservativo ${ }^{26}$. Essa situação se agrava quando as mulheres já são esterilizadas e não necessitam se proteger de uma gravidez indesejada ${ }^{27}$. 
As campanhas de prevenção do MS focam a prática do sexo seguro - "use camisinha" - e as consequências de se expor ao risco. No entanto, a julgar pelo avanço da epidemia, principalmente entre a população feminina cisgênero, tais campanhas não têm sido eficazes ${ }^{28}$. Os meios de intervenção deveriam produzir transformações, mas para isso é necessário conhecer as crenças e práticas sexuais do local onde se quer intervir ${ }^{29}$.

Compreender o aumento da infecção por HIV em mulheres não é tarefa fácil, visto que a aids carrega o estigma de doença vergonhosa, fortemente associada a comportamentos desvalorizados moralmente. A condição social da mulher torna essa tarefa ainda mais difícil, principalmente porque a prevenção da aids está ligada ao controle do comportamento sexual, que guarda relação com a reprodução e os papéis de gênero ${ }^{30}$.

Publicado pelo MS em março de 2007 e atualizado em edições posteriores, o Plano Integrado de Enfrentamento da Feminização da Epidemia de Aids e Outras DST discute cenários em que o gênero feminino é mais vulnerável e propõe 12 estratégias para diminuir o número de casos entre mulheres. Assim, o plano tanto identifica as causas de vulnerabilidade da mulher como sugere importantes atividades de intervenção para alcançar as metas propostas ${ }^{31}$.

Após mais de três décadas de enfrentamento do HIV/aids, a epidemia continua sendo assunto importante e atual, tendo em vista que a sexualidade humana é um de seus aspectos fundamentais ${ }^{29}$. Quanto à vulnerabilidade das mulheres, muitos são os fatores que a definem, como faixa etária e grau de instrução, e que não podem ser negligenciados se queremos adotar medidas eficazes de combate à doença ${ }^{32-34}$.

\section{Resultados e discussão}

O papel social da mulher está em transformação. Inicialmente educadas para permanecer no espaço doméstico e serem donas de casa, mais recentemente as mulheres vêm se inserindo no mercado de trabalho. Contudo, no campo afetivo, é possível observar a permanência desse lugar do feminino, forjado no final do século XIX, de dependência e submissão ao homem, o que é um dos fatores de vulnerabilidade para a infecção pelo HIV ${ }^{11,15,21,22}$. A valorização da relação estável e a crença de que a fidelidade garante proteção fecham os olhos para a possibilidade de que o cônjuge mantenha relações sexuais com outras pessoas, inclusive com outros homens, algo comum numa sociedade que estimula um comportamento sexual dual, que separa o marido/companheiro/namorado do homem que está sempre disponível para vivências sexuais fora do contexto afetivo ou familiar ${ }^{12,13,15,17,20,21,23}$.

Com receio de perder o status social que o relacionamento estável promove - seja ele um namoro ou casamento -, ou por medo de perder a confiança do companheiro, a discussão sobre adotar práticas sexuais seguras, como o uso de preservativos, é deixada de lado. Por outro lado, quando o assunto é contracepção, a interlocução é mais aceita ${ }^{17,20}$. Isso se deve a crenças e valores morais que a sociedade ocidental credita ao casamento (e às relações estáveis de modo geral) atributos como amor, respeito, fidelidade, cumplicidade e confiança ${ }^{26}$.

A visão romanceada do amor pode levar ao abandono de práticas sexuais protegidas e à falsa crença de que, numa relação estável, não há risco de infecção pelo HIV (ou por outra infecção sexualmente transmissível) ${ }^{26}$. Assim, não surpreende que Barroso, Miranda e Pinheiro ${ }^{27}$ tenham encontrado um ponto em comum entre mulheres infectadas por seus parceiros: todas eram fiéis aos seus companheiros e, por acreditarem na reciprocidade de sentimentos, contraíram o HIV.

Até mesmo entre a população adolescente prevalece o pensamento de que cabe ao homem portar o preservativo e tomar a iniciativa de usá-lo, delegando à mulher um papel passivo e dependente na relação, com pouca influência nas decisões tomadas na esfera sexual ${ }^{24,25}$. A juventude é outro importante fator de vulnerabilidade, pois combina imaturidade biopsicossocial, dependência econômica, desconhecimento de direitos e menor acesso a serviços de saúde. Além disso, é comum que mulheres jovens se relacionem com parceiros mais velhos e, em muitos casos, sofram violência sexual ${ }^{32,33}$.

Em nossa sociedade, as mulheres ainda são cotidianamente submetidas à dominação patriarcal, à subordinação e à violência. A normatividade social determina que elas devem ser femininas, delicadas, carinhosas, sensíveis e submissas, 
enquanto se espera que homens exteriorizem sua masculinidade sendo dominadores, ativos, agressivos e másculos ${ }^{29,30}$. Nesse sentido, é possível que mulheres mais velhas, por terem sido educadas num contexto em que a esposa deve obediência ao marido, apresentem nível menor de abertura para dialogar sobre a vida sexual, o que as torna ainda mais vulneráveis ${ }^{12,19}$.

Outro aspecto significativo é a associação entre preservativo e desconforto ou diminuição do prazer, o que reduz sua utilização e aumenta o risco de infecção ${ }^{18,24,29}$. A preocupação com o sexo seguro parece restrita ao início da relação, enquanto ocorre um período de avaliação mútua para validar uma "mudança de fase" marcada pela dispensa do uso de preservativo. Isso acontece até mesmo em relações extraconjugais, o que aumenta o risco de infecção para todos os participantes da relação ${ }^{16,18}$.

Quando suspeitam de traição, algumas mulheres exigem que seus parceiros passem a usar camisinha nas relações conjugais, mas essa exigência costuma durar pouco tempo ${ }^{16,18}$. Ainda que se faça um exame laboratorial para descartar a possibilidade de infecção, o resultado negativo pode ser falso, pois os anticorpos só são detectados no sangue após a chamada "janela imunológica" (para o teste rápido, 30 dias após a exposição ao $\mathrm{HIV})^{35}$. Além disso, a testagem só reflete a condição sorológica do sujeito até o momento do exame. Caso relações sexuais desprotegidas continuem a ocorrer, o risco de infecção continuará presente.

As campanhas de prevenção à infecção pelo HIV concentram-se na utilização de preservativos e são massificadas apenas na época do carnaval. Essas campanhas, incapazes de conter a epidemia, não levam em consideração as relações de poder entre homem e mulher e as diferentes realidades socioeconômicas, culturais e religiosas ${ }^{14,21,22,28,36}$.

Por meio do Plano Integrado de Enfrentamento da Feminização da Epidemia de Aids e Outras DST, o MS e a Secretaria Especial de Políticas para as Mulheres convocam a sociedade civil organizada, gestores e participantes de movimentos sociais para desenvolver, monitorar e avaliar políticas, programas, ações e estratégias equitativas e integrais para promover o acesso universal à prevenção, diagnóstico, tratamento e apoio às pessoas que vivem com HIV e aids ${ }^{37}$. Como forma de ampliar o acesso à saúde, vislumbra-se, entre outras ações, a integração do plano à Estratégia Saúde da Família e ao Projeto Saúde e Prevenção nas Escolas, nas esferas municipal, estadual e federal ${ }^{31}$.

O contínuo crescimento do número de infectados, com cerca de 40 mil novos casos de aids por ano ${ }^{4}$, revela que as ações de enfrentamento ainda são incipientes. O quadro político atual torna a situação ainda mais crítica. Áreas da educação e da saúde (dentre elas a Estratégia Saúde da Família) vêm sendo enfraquecidas com cortes de recursos, e uma onda conservadora busca apagar temas como o da epidemia de HIV dos espaços de debate e da estruturação de políticas públicas.

Em meio a todas essas dificuldades, em especial à de autoproteção feminina em nosso contexto sociocultural, os dados epidemiológicos nacionais revelam que a incidência de infecções entre homens que fazem sexo com homens está em ascensão ${ }^{4}$. Considerando o fato de que esses homens também mantêm relações heterossexuais, é possível que o número de mulheres infectadas continue a aumentar nos próximos anos. Assim, é necessário dar mais atenção a esse fato e implementar medidas que protejam a população feminina.

Conforme propõe a bioética feminista, é necessário mudar relações sociais que se caracterizam pela dominação humana e pela subordinação $e$ que impedem o exercício da liberdade ${ }^{38}$. É preciso olhar criticamente as estruturas de poder estabelecidas e seu potencial lesivo sobre os mais vulneráveis para buscar mecanismos de reparação ${ }^{39}$.

\section{Considerações finais}

A pesquisa mostrou que, diante da complexidade das relações e da desigualdade entre gêneros, as campanhas de prevenção ao HIV centradas no uso do preservativo masculino não têm surtido efeito na contenção da epidemia, especialmente no que se refere a uma parte da população feminina - mulheres infectadas em relações heterossexuais. Conter o avanço do vírus entre as mulheres exige ações mais eficazes, que considerem diversas questões, como condições socioeconômicas e culturais de cada região do país e relações de poder entre homens e mulheres, que são mais desiguais em determinados contextos. 
É fundamental esclarecer a população sobre a importância do diálogo entre parceiros e a necessidade do autocuidado na vivência do prazer sexual, inclusive em relacionamentos estáveis. Devem-se enfatizar a responsabilidade com o outro e o dever de zelar pela saúde e bem-estar da pessoa com que nos relacionamos, o que favorece a negociação do uso de preservativos não apenas como método anticoncepcional, mas também como medida de proteção.

As equipes de atenção básica, em especial da Estratégia Saúde da Família, deveriam desempenhar um papel relevante nesse trabalho educativo. O vínculo com a população adscrita facilita um diálogo mais franco entre usuários e profissionais de saúde. O sexo ainda está cercado por tabus, e essa relação mais próxima permite que o assunto seja abordado de forma mais direta, com o aprofundamento necessário. Momentos de reflexão conjunta, com a participação de usuários da saúde (mulheres e homens) e equipe profissional, também podem favorecer métodos como o estudo de caso e a problematização que ampliam a capacidade de refletir sobre o tema e empoderar o indivíduo para adotar um comportamento seguro e consciente.

As atividades voltadas à promoção da saúde e prevenção de doenças podem inclusive preparar as mulheres para que sejam agentes multiplicadores das informações educativas em seus lares, com descendentes e demais familiares. Dessa forma, o olhar voltado às próprias necessidades em saúde se amplia e passa a transformar a comunidade. Por isso é necessário investir no empoderamento feminino, uma valiosa ferramenta de transformação social num contexto em que é imprescindível mudar comportamentos e desconstruir o padrão hegemônico de dominação das mulheres pelos homens.

A educação para a saúde pode ainda ganhar mais força com parcerias entre equipes de saúde, escolas e instituições religiosas pertencentes à comunidade onde estão inseridas. É necessário discutir as relações de poder estabelecidas em nossa sociedade e mostrar que a desigualdade de gêneros prejudica a vida das mulheres.

Gestores e profissionais de saúde devem estar atentos às particularidades epidemiológicas de cada região do Brasil, trabalhando junto com a população e buscando conhecer o comportamento das pessoas na localidade de atuação. Assim, o investimento em saúde pode ser direcionado a medidas que de fato consigam atingir o objetivo almejado: reduzir os casos de infecção por HIV no país.

A capacidade de lidar com questões de gênero e sexualidade - com um olhar para o outro que, por vezes, confronta as próprias crenças e valores - precisa ser trabalhada desde o período de formação. A inclusão da bioética, de forma transversal, nos currículos das graduações em saúde promove uma prática crítica e reflexiva, voltada ao desenvolvimento de competências morais que capacitam o discente para agir de forma justa e respeitosa, livre de preconceitos e fundamentalismos opressores. A educação permanente é uma aliada na tarefa de fomentar discussões sobre o agir ético em saúde e direitos humanos, buscando romper com a lógica patriarcal e machista, auxiliando as mulheres a perceber com clareza os riscos de práticas sexuais inseguras e capacitando-as para o autocuidado.

\section{Referências}

1. Brasil. Instituto Nacional do Seguro Social. Resolução INSS/DC $n^{\circ} 089$, de 5 de abril de 2002. Aprova a norma técnica de avaliação da incapacidade laborativa para fins de benefícios previdenciários em HIV/aids [Internet]. Genebra: International Labour Organization; 2002 [acesso 28 maio 2019]. Disponível: https://bit.ly/3aUslD7

2. Brasil. Ministério da Saúde. História da aids [Internet]. 2018 [acesso 28 maio 2019]. Disponível: https://bit.ly/331E4LZ

3. Cohen J, Torres C. HIV-associated cellular senescence: a contributor to accelerated aging. Ageing Res Rev [Internet]. 2017 [acesso 28 maio 2019];36:117-24. DOI: 10.1016/j.arr.2016.12.004

4. Brasil. Ministério da Saúde. Boletim Epidemiológico HIV/AIDS 2020 [Internet]. 2020 [acesso 21 março 2021]. Disponível: https://bit.ly/3t94lgg 
5. Brasil. Ministério da Saúde. Boletim Epidemiológico HIV/Aids 2018 [Internet]. 2018 [acesso 28 maio 2019]. Disponível: https://bit.ly/3t6Xrhf

6. Jesus JG. Trans-formações: poder e gênero nos novos tempos. In: Anais do $18^{\circ}$ Congresso Brasileiro de Psicodrama; 6-9 jun 2012; Brasília. São Paulo: Federação Brasileira de Psicodrama; 2012.

7. Brito AM, Castilho EA, Szwarcwald CL. Aids e infecção pelo HIV no Brasil: uma epidemia multifacetada. Rev Soc Bras Med Trop [Internet]. 2000 [acesso 28 maio 2019];34(2):207-17. DOI: 10.1590/ S0037-86822001000200010

8. Sadala MLA, Marques SA. Vinte anos de assistência às pessoas vivendo com HIV/AIDS no Brasil: a perspectiva de profissionais de saúde. Cad Saúde Pública [Internet]. 2006 [acesso 30 abr 2021];22(11):2369-78. DOI: 10.1590/S0102-311X2006001100011

9. Brasil. Ministério da Saúde. Qual é a diferença entre a PrEP e PEP [Internet]. 2018 [acesso 21 mar 2021]. Disponível: https://bit.ly/336Be8i

10. Brasil. Ministério da Saúde. PEP (Profilaxia Pós-Exposição ao HIV) [Internet]. 2018 [acesso 21 mar 2021]. Disponível: https://bit.ly/3xC4W3c

11. Biasoli-Alves ZMM. Continuidades e rupturas no papel da mulher brasileira no século XX. Psic Teor Pesq [Internet]. 2000 [acesso 28 maio 2019];16(3):233-9. DOI: 10.1590/S0102-37722000000300006

12. Silva CM, Lopes FMVM, Vargens OMC. A vulnerabilidade da mulher idosa em relação à aids. Rev Gaúcha Enferm [Internet]. 2010 [acesso 28 maio 2019];31(3):450-7. DOI: 10.1590/S1983-14472010000300007

13. Madureira VSF, Trentini M. Relações de poder na vida conjugal e prevenção da aids. Rev Bras Enferm [Internet]. 2008 [acesso 28 maio 2019];61(5):637-42. DOI: 10.1590/S0034-71672008000500017

14. Gonçalves EH, Varandas R. O papel da mídia na prevenção do HIV/aids e a representação da mulher no contexto da epidemia. Ciênc Saúde Coletiva [Internet]. 2005 [acesso 28 maio 2019];10(1):229-35. DOI: 10.1590/S1413-81232005000100029

15. Marques JS Jr, Gomes R, Nascimento EF. Masculinidade hegemônica, vulnerabilidade e prevenção ao HIV/aids. Ciênc Saúde Coletiva [Internet]. 2012 [acesso 28 maio 2019];17(2):511-20. DOI: 10.1590/ S1413-81232012000200024

16. Sousa MCP, Espírito Santo ACG, Motta SKA. Gênero, vulnerabilidade das mulheres ao HIV/aids e ações de prevenção em bairro da periferia de Teresina, Piauí, Brasil. Saúde Soc [Internet]. 2008 [acesso 28 maio 2019];17(2):58-68. DOI: 10.1590/S0104-12902008000200007

17. Madureira VSF, Trentini M. Da utilização do preservativo masculino à prevenção de DST/aids. Ciênc Saúde Coletiva [Internet]. 2008 [acesso 28 maio 2019];13(6):1807-16. DOI: 10.1590/S1413-81232008000600015

18. Rodrigues DAL, Praça NS. Mulheres com idade igual ou superior a 50 anos: ações preventivas da infecção pelo HIV. Rev Gaúcha Enferm [Internet]. 2010 [acesso 28 maio 2019];31(2):321-7. DOI: 10.1590/ S1983-14472010000200017

19. Miranda-Ribeiro P, Simão AB, Caetano AJ, Lacerda MA, Torres MEA. Perfis de vulnerabilidade feminina ao HIV/aids em Belo Horizonte e Recife: comparando brancas e negras. Saúde Soc [Internet]. 2010 [acesso 28 maio 2019];19(2):21-35. DOI: 10.1590/S0104-12902010000600004

20. Praça NS, Gualda DMR. Percepção de risco para HIV/aids de mulheres faveladas segundo o modelo de crença em saúde. Rev Esc Enferm USP [Internet]. 2001 [acesso 28 maio 2019];35(1):54-9. DOI: 10.1590/ S0080-62342001000100009

21. Amaro STA. A questão da mulher e a aids: novos olhares e novas tecnologias de prevenção. Saúde Soc [Internet]. 2005 [acesso 28 maio 2019];4(2):89-99. DOI: 10.1590/S0104-12902005000200010

22. Carvalho FT, Piccinini CA. Aspectos históricos do feminino e do maternal e a infecção pelo HIV em mulheres. Ciênc Saúde Coletiva [Internet]. 2008 [acesso 28 maio 2019];13(6):1889-98. DOI: 10.1590/ S1413-81232008000600024

23. Praça NS, Gualda DMR. Risco de infecção pelo HIV: como mulheres moradoras em uma favela se percebem na cadeia de transmissão do vírus. Rev Latinoam Enfermagem [Internet]. 2003 [acesso 28 maio 2019];11(1):14-20. DOI: 10.1590/S0104-11692003000100003 
24. Sampaio J, Santos RC, Callou JLL, Souza BBC. Ele não quer camisinha e eu quero me prevenir: exposição de adolescentes do sexo feminino às DST/aids no semi-árido nordestino. Saúde Soc [Internet]. 2011 [acesso 28 maio 2019];20(1):171-81. Disponível: https://bit.ly/3ucGXpg

25. Nogueira C, Saavedra L, Costa C. (In)Visibilidade do género na sexualidade juvenil: propostas para uma nova concepção sobre a educação sexual e a prevenção de comportamentos sexuais de risco. Pro-Posições [Internet]. 2008 [acesso 28 maio 2019];19(2):59-79. DOI: 10.1590/S0103-73072008000200006

26. Maia C, Guilhem D, Freitas D. Vulnerabilidade ao HIV/aids de pessoas heterossexuais casadas ou em união estável. Rev Saúde Pública [Internet]. 2008 [acesso 28 maio 2019];42(2):242-8. DOI: 10.1590/ S0034-89102008005000004

27. Barroso MGT, Miranda CCL, Pinheiro PNC. A aids sob o olhar da companheira contaminada. Rev Bras Enferm [Internet]. 1998 [acesso 28 maio 2019];51(3):393-402. DOI: 10.1590/S0034-71671998000300005

28. López LC. Uma análise das políticas de enfrentamento ao HIV/aids na perspectiva da interseccionalidade de raça e gênero. Saúde Soc [Internet]. 2011 [acesso 28 maio 2019];20(3):590-603. DOI: 10.1590/ S0104-12902011000300006

29. Lima MLC, Moreira ACG. Aids e feminização: os contornos da sexualidade. Rev Mal-Estar Subj [Internet]. 2008 [acesso 28 maio 2019];8(1):103-18. Disponível: https://bit.ly/3nBqhol

30. Paiva MS. A feminilização da aids: uma questão de gênero? Rev Bras Enferm [Internet]. 1999 [acesso 28 maio 2019];52(1):8. DOI: 10.1590/S0034-71671999000100002

31. Brasil. Ministério da Saúde. Plano integrado de enfrentamento da feminização da epidemia de aids e outras DST [Internet]. Brasília: Ministério da Saúde; 2007 [acesso 28 maio 2019]. Disponível: https://bit.ly/3u9jfdq

32. Taquette S. Feminização da aids e adolescência. Adolescência \& Saúde [Internet]. 2009 [acesso 28 maio 2019];6(1):33-40. Disponível: https://bit.ly/3aQhPwU

33. Taquette SR, Matos HJ, Rodrigues AO, Bortolotti LR, Amorim E. A epidemia de AIDS em adolescentes de 13 a 19 anos, no município do Rio de Janeiro: descrição espaço-temporal. Rev Soc Bras Med Trop [Internet]. 2011 [acesso 28 maio 2019];44(4):467-70. DOI: 10.1590/S0037-86822011000400013

34. Mombelli MA, Barreto MS, Arruda GO, Marcon SS. Epidemia da aids em tríplice fronteira: subsídios para a atuação profissional. Rev Bras Enferm [Internet]. 2015 [acesso 28 maio 2019];68(3):429-37. DOI: 10.1590/0034-7167.2015680308i

35. Brasil. Ministério da Saúde. O que é janela imunológica? Eu posso ter HIV e resultado negativo no teste? Como eu posso ter certeza de que meu resultado é mesmo negativo? [Internet]. 2018 [acesso 21 mar 2021]. Disponível: https://bit.ly/2QBqJaF

36. Santos NJS, Barbosa RM, Pinho AA, Villela WV, Aidar T, Filipe EMV. Contextos de vulnerabilidade para o HIV entre mulheres brasileiras. Cad Saúde Pública [Internet]. 2009 [acesso 28 maio 2019];25(2):5321-33. DOI: 10.1590/S0102-311X2009001400014

37. Brasil. Ministério da Saúde. Plano integrado de enfrentamento da feminização da epidemia de aids e outras DST versão revisada [Internet]. Brasília: Ministério da Saúde; 2011. p.38 [acesso 28 julho 2017]. Disponível: https://bit.ly/3w1RRym

38. Diniz D, Vélez ACG. Bioética feminista: a emergência da diferença. Rev Estud Fem [Internet]. 1999 [acesso 22 março 2021]; 6(2):255-64. Disponível: https://bit.ly/3t6jkNB

39. Diniz D, Guilhem D. Bioética feminista na América Latina: a contribuição das mulheres. Rev Estud Fem [Internet]. 1999 [acesso 22 mar 2021];16(2):599-612. DOI: 10.1590/S0104-026X2008000200015 
Luciana Narciso da Silva Campany - Doutora - luciana.narciso@gmail.com

(D) 0000-0003-0481-2367

Daniela Murta Amaral - Doutora - murtadaniela@gmail.com

(D) 0000-0002-4854-3157

Roberta Nascimento de Oliveira Lemos dos Santos - Doutora - roberta_o_lemos@hotmail.com (D) 0000-0001-9658-1185

\section{Correspondência}

Luciana Narciso da Silva Campany - Rua Leopoldo Bulhões, 1480, sala 919.

CEP 21041-210. Manguinhos/RJ, Brasil.

Participação dos autores

Luciana Narciso da Silva Campany foi responsável pela ideia inicial do estudo e, junto com Daniela Murta Amaral e Roberta Lemos dos Santos, estabeleceu a metodologia da pesquisa e redigiu o artigo.

Recebido: 29.6 .2019

Revisado: 11.11.2020

Aprovado: 23.3 .2021 